\title{
Evaluación del efecto protector de una autovacuna elaborada a partir de poxvirus de palomas
}

\author{
Evaluation of the effect of a pigeon poxvirus autogenous vaccine
}

\author{
A Sánchez, LM Valdés, LE Rangel, L Cobos-Marín* \\ Facultad de Medicina Veterinaria y Zootecnia, Universidad Nacional Autónoma de México, Ciudad de México, México.
}

\begin{abstract}
SUMMARY
The aim of this study was to compare the protective effectiveness of a homologous vaccine against pigeon avipoxvirus with that of a commercial heterologous vaccine against chicken avipoxvirus, by challenging pigeons with pigeon avipoxvirus. The pigeon avipoxvirus was isolated from skin lesions of infected pigeons and then inocculated on chick embryo chorioallantoic membrane (CAM). The virus was identified by histopathology, polymerase chain reaction and restriction enzyme analysis. Subsequently, the virus was attenuated by several passages in CAM and used as a vaccine when reaching a viral titer of 104.37 DIEP50\%/mL. Pigeons vaccinated with the homologous vaccine $(\mathrm{n}=20)$ achieved serum neutralizing titers of $1 / 61,5$ while those vaccinated with the heterologous vaccine $(n=20)$ achieved serum neutralizing titers of zero. Finally, when animals were challenged with pigeon avipoxvirus, all pigeons from the homologous vaccine group were protected, while in the heterologous vaccine and non-vaccinated control ( $\mathrm{n}=20$ ) groups, no protection was achieved. In conclusion, the use of an homologous vaccine against poxvirus when working with pigeons, generates neutralizing antibodies and confers a much better protection against infection when compared to the use of commercial vaccines made against the chicken poxvirus.
\end{abstract}

Palabras clave: viruela, vacuna, palomas.

Key words: smallpox, chicken pox, vaccine, pigeons.

\section{INTRODUCCIÓN}

La colombofilia se refiere a la crianza de las palomas con fines de ornato y deportivos. Actualmente, la crianza deportiva se practica en más de 58 países afiliados a la Federación Colombófila Internacional (FCI), con sede en Bélgica, y que tiene registrados alrededor de un millón de colombófilos, siendo los países europeos y asiáticos los de mayor afición $\left({ }^{1}\right)$. En América Latina, esta es una práctica que se ha ido difundiendo, y actualmente se cuenta con una Asociación Ibero Latino-Americana de Colombofilia (AILAC), con 417.500 palomas y 12.000 palomares registrados ( ${ }^{1}$ http://www.fcipigeons.com/FCIstart.htm). Sin embargo, pocos estudios se realizan en este tipo de aves y las vacunas existentes en Europa no se encuentran disponibles en nuestros países. Por ello, es necesaria la implementación de prácticas sanitarias que garanticen la salud de los animales, cuando son sometidos al estrés de las competencias.

La viruela aviar es una enfermedad que afecta a las palomas y es causada por un virus de la familia Poxviridae, subfamilia Chordopoxvirinae y género Avipoxvirus (Tudor 1991, Wernery 2000). La transmisión de esta infección ocurre por vectores, que son los mosquitos (Tudor 1991,

\footnotetext{
Aceptado: 16.06.2011.

* laura.cobosmarin@gmail.com

1 FCI [página inicial en Internet]. Halle, Bélgica: Fédération Colombophile Internationale [update 2010; citado enero 2011]. Disponible en http://www.fcipigeons.com
}

De Hart y Devriese 2000). Las manifestaciones conocidas de la enfermedad son: cutánea, diftérica y atípica (De Hart y Devriese 2000, Weli y col 2004). La morbilidad en palomas jóvenes (menores de 1 año) puede llegar a 45\% y hasta $25 \%$ en adultas (mayores a un año); mientras que la mortalidad puede alcanzar un $49 \%$ y un 7,5\% respectivamente (Das y col 2005, Marlier y Vindevogel 2006).

La prevención de esta enfermedad con la vacunación es muy importante, debido a que no existe un tratamiento curativo. Esta vacuna genera inmunidad dos semanas post-aplicación, con duración de 1 año (Tudor 1991, Marlier y Vindevogel 2006). Debido a que en México no hay disponible una vacuna específica contra la viruela de palomas, dichos animales son inmunizados con vacunas de pollo; a pesar de ello, los propietarios reportan una alta frecuencia de infecciones por poxvirus de paloma cuando los animales de distintos palomares se mezclan para las competencias de vuelo.

El objetivo del presente trabajo fue elaborar una vacuna específica de avipoxvirus de paloma y comparar la respuesta a su aplicación y la protección conferida por la misma, contra las que genera una vacuna comercial de pollo.

\section{MATERIAL Y MÉTODOS}

El trabajo se realizó en el Laboratorio de Virología del Departamento de Microbiología e Inmunología y en el palomar del Departamento de Reproducción de la Facultad de Medicina Veterinaria y Zootecnia (FMVZ) de la Universidad Nacional Autónoma de México (UNAM). 


\section{AISLAMIENTO VIRAL}

Se obtuvieron costras de palomas que presentaban lesiones sugerentes a viruela (afecciones cutáneas nodulares proliferativas a fibronecróticas en las partes del cuerpo sin plumas, así como en la mucosa de las vías respiratorias superiores) (Tripathy y Reed 2003). Las costras se maceraron en seco, se les agregó solución amortiguadora de fosfato salino hasta lograr una concentración del $10 \%$. La suspensión se centrifugó a $873 \times$ g por 10 min para obtener un sobrenadante (suspensión viral), al que se le adicionaron 10.000 UI de penicilina (Lakeside®, USA) y $10 \mathrm{mg}$ de estreptomicina (Pisa ${ }^{\circledR}$, México) por $\mathrm{mL}$ para eliminar contaminantes bacterianos. La ausencia de contaminación bacteriana en la suspensión viral se verificó por la siembra de $0,1 \mathrm{~mL}$ en medios bacteriológicos (agar triptosa y caldo tioglicolato) que se incubaron a $37^{\circ} \mathrm{C}$ por $48 \mathrm{~h}$ (Cunningham 1971).

Se inocularon $100 \mu \mathrm{L}$ de la suspensión viral en embriones de pollo (EP) de 10 a 12 días de edad vía membrana corioalantoidea (MCA) por el método de falsa cámara de aire. Los embriones fueron incubados durante 5 días a $37{ }^{\circ} \mathrm{C}$ y se revisaron diariamente para verificar la mortalidad. Al quinto día se sacrificaron por enfriamiento (colocándolos en el congelador por 2 h) para obtener las MCA. Aquellas membranas que presentaron edema se maceraron en condiciones de esterilidad con ayuda de un mortero, arena estéril (como abrasivo) y solución amortiguadora de fosfato salino (Cunningham 1971). El macerado se centrifugó a $873 \times$ g por 10 min y se obtuvo una segunda suspensión viral que se sometió a la prueba de esterilidad bacteriana. De esta segunda suspensión viral se hicieron pases ciegos en MCA de EP, hasta observar la presencia de lesiones (edema, engrosamiento y pústulas blanquecinas).

\section{IDENTIFICACIÓN VIRAL}

Para la identificación del virus aislado a partir de costras de lesiones sugerentes a viruela de palomas se realizaron las tres pruebas que se mencionan a continuación.

Identificación histopatológica. Se hicieron cortes histológicos a partir de las MCA con lesiones sugestivas de infección por avipoxvirus y se tiñeron con hematoxilina y eosina, en busca de cuerpos de inclusión intracitoplasmáticos (Bollinger), hallazgo característico de la infección viral causada por avipoxvirus (Tripathy 1993, Gerlach H 1994, Krautwald 2007).

Identificación molecular, por la reacción en cadena de la polimerasa $(P C R)$. Se extrajo ADN a partir de $25 \mathrm{mg}$ de MCA con lesiones sugerentes de infección por avipoxvirus. Para ello, el tejido se homogeneizó con $1 \mathrm{~mL}$ de DNAzol-Reagent (Invitrogen ${ }^{\circledR}$, USA) y se centrifugó a $10.000 \times \mathrm{g}$ a $4{ }^{\circ} \mathrm{C}$ durante $10 \mathrm{~min}$. El sobrenadante se pasó a otro tubo, se le agregaron $0,5 \mathrm{~mL}$ de etanol, se incubó 3 min y se centrifugó durante 2 min a $4.000 \times \mathrm{g}$ a $4{ }^{\circ} \mathrm{C}$. El precipitado de ADN se lavó 2 veces con $1 \mathrm{~mL}$ de etanol al 75\%, se dejó secar por 2 min y se disolvió en $300 \mu \mathrm{L}$ de $\mathrm{NaOH} 8 \mathrm{mM}$. El ADN se cuantificó en el bioespectrofotómetro (marca Ependorf®).

Para la PCR se utilizó un volumen final de reacción de $25 \mu \mathrm{L}$, que contenían $1 \mu \mathrm{g}$ de ADN, 1,5 unidades de Taq polimerasa, 1,5 mM de $\mathrm{MgCl}_{2}, 200 \mu \mathrm{M}$ de dNTP's, solución reguladora, 12,5 pmol de cada uno de los iniciadores descritos por Lee y Lee (1997) que amplifican una región de 578pb, dentro del gen $4 \mathrm{~b}$ (P1: 5'-CAGCAGGTGCTAAACAACAA-3'; P2: 5'-CGGTAGCTTAACGCCGAATA-3'). La reacción de la PCR se realizó en el termociclador (marca Techne®,) con un primer ciclo de denaturación inicial de 2 min a $94{ }^{\circ} \mathrm{C}$, seguido por 35 ciclos de $1 \mathrm{~min}$ a $94{ }^{\circ} \mathrm{C}$ de denaturación, 1 min a $60^{\circ} \mathrm{C}$ de alineamiento y 1 min a $72^{\circ} \mathrm{C}$ de extensión, terminando con un ciclo de 2 min a $72^{\circ} \mathrm{C}$ de extensión final.

De la misma forma se trabajó con un avipoxvirus de pollo, obtenido a partir de una vacuna comercial de viruela aviar (Maver®, México), elaborada con cultivo de poxvirus de gallina, con un título de no menos de $10^{4} \mathrm{DIEP}_{50 \%} / \mathrm{mL}$ (según especificaciones del fabricante), para utilizarlo como control positivo.

Al final, $5 \mu \mathrm{L}$ de ambos productos de PCR (pollo y paloma) se corrieron en un gel de agarosa al $1 \%$ a 85 volts por $1 \mathrm{~h}$, que se tiñó con bromuro de etidio al $0,01 \%$ durante $10 \mathrm{~min}$, y se observó en el UV-Transiluminador (marca Benchtop®).

Identificación de especies virales, por análisis de restricción enzimática (REA). A los productos resultantes de la PCR (paloma y pollo) se les realizó el análisis de restricción enzimática (Lüschow y col 2004), con la enzima MseI (Biolabs®, USA), que genera 3 fragmentos de 250, 118 y $95 \mathrm{pb}$ para el poxvirus de paloma y de 252,177 y $149 \mathrm{pb}$ para el de pollo. El análisis se desarrolló en un volumen total de $20 \mu \mathrm{L}$ al que se le pusieron: $1 \mu \mathrm{L}$ de enzima equivalente a 10 unidades, $2 \mu \mathrm{L}$ de solución amortiguadora (Biolabs $®$, USA), $12 \mu \mathrm{L}$ de $\mathrm{H}_{2} \mathrm{O}$ y $5 \mu \mathrm{L}$ de las muestras de PCR. Las mezclas de reacción se incubaron por $1 \mathrm{~h}$ a $37^{\circ} \mathrm{C}$, después se corrieron $5 \mu \mathrm{L}$ en un gel de agarosa al $3 \%$ por 45 min a 85 volts. El gel se tiñó 15 min con bromuro de etidio (al 0,01\%) y se observó en el UV-Transiluminador (marca Benchtop® ), con luz ultravioleta.

\section{ELABORACIÓN DE LA VACUNA HOMÓLOGA}

A partir de las MCA que presentaron edema durante el aislamiento viral se hizo una nueva suspensión viral, que fue inoculada en EP (de la manera descrita en el aislamiento viral), realizando pases hasta que se observaron lesiones (engrosamiento, edema y pústulas blanquecinas en MCA) y se procedió a titular el virus por el método estadístico de Reed y Muench (Reed y Muench 1938). Con esta suspensión viral se inocularon dos palomas para 
verificar que produjera una reacción local característica de la vacunación y que, por lo tanto, pudiera ser empleada como vacuna.

\section{VACUNACIÓN}

Se utilizaron 60 pichones de entre 13 y 17 semanas de edad, seleccionados aleatoriamente. Los pichones se mantuvieron en aislamiento, en grupos de 10 animales, dentro de jaulas de $90 \mathrm{~cm}$ de largo por $65 \mathrm{~cm}$ de ancho y $40 \mathrm{~cm}$ de alto, y se les proporcionó agua y alimento ad libitum.

Se formaron tres grupos experimentales: Grupo control: $(n=20)$ animales sin vacunar y puestos en aislamiento hasta el momento del desafío. Grupo vacunado contra poxvirus de paloma: $(n=20)$ animales inmunizados por punción en el pliegue de la pierna, con $0,1 \mathrm{~mL}$ de la vacuna homóloga experimental de poxvirus de paloma. Grupo vacunado contra poxvirus de pollo: $(n=20)$ animales que recibieron una dosis de vacuna heteróloga comercial de poxvirus de gallina (con un título de $10^{4} \mathrm{DIEP}_{50 \%} / \mathrm{mL}$ ), según especificaciones del fabricante. La respuesta a la vacunación se verificó mediante la observación de lesiones posvacunales como enrojecimiento, formación de una pápula, de vesículas y/o de pústulas y costras durante tres semanas posvacunación. Se registró el tiempo que tardaron en presentarse las lesiones, así como el tiempo de permanencia de éstas.

\section{SERONEUTRALIZACIÓN VIRAL}

Se hizo por el método $\beta$ (AAAP 1989, Murphy y col 1999), con $100 \mathrm{DIEP}_{50 \%} / \mathrm{mL}$ de virus de paloma. Para ello, un día antes del desafío se obtuvo una muestra de $400 \mu \mathrm{L}$ de sangre de cada animal (Krautwald 2007) mediante el corte de uña. Los sueros se separaron incubando las muestras a $37{ }^{\circ} \mathrm{C}$ por $4 \mathrm{~h}$, se mezclaron en un lote por grupo y se congelaron a $-20{ }^{\circ} \mathrm{C}$ hasta su utilización.

Cada lote de suero se inactivó durante $30 \mathrm{~min}$ a $56^{\circ} \mathrm{C}$ y se hicieron ocho diluciones dobles seriadas, iniciando en
1/5 (480 $\mu \mathrm{L}$ de PBS y $120 \mu \mathrm{L}$ del suero). Cada dilución se incubó durante $30 \mathrm{~min}$ a temperatura ambiente con $300 \mu \mathrm{L}$ del virus (Murphy y col 1999). Posteriormente, la mezcla suero-virus se inoculó en MCA de EP como se describió para el aislamiento viral, utilizando 5 embriones por dilución. Finalmente, se determinó el título por el método estadístico de Reed y Muench (Reed y Muench 1938).

DESAFÍO

A las tres semanas posvacunación, se desafiaron los tres grupos con poxvirus aislado de palomas infectadas naturalmente, adicionado con glicerol al $20 \%$ y con un título de $10^{4} \mathrm{DIEP}_{50 \%} / \mathrm{mL}$. Para la inoculación se utilizó una brocha de cerdas duras impregnada con $50 \mu \mathrm{L}$ de la suspensión viral, y se realizó una excoriación de $2 \times$ $2 \mathrm{~cm}$ en la piel de la región ventral caudal a la quilla. $\mathrm{La}$ presencia de lesiones se registró durante las tres semanas siguientes al desafío, considerándose como protegidos aquellos animales que no presentaron lesiones locales (Tudor 1991, Tripathy y Reed 2003).

\section{RESULTADOS Y DISCUSIÓN}

La suspensión obtenida a partir de las costras de lesiones de palomas con viruela aviar, preparada para realizar el aislamiento viral, resultó negativa en la prueba de contaminación bacteriana. El virus requirió en total seis pases ciegos en EP para que se presentaran las lesiones características de la infección por avipoxvirus: pústulas blanquecinas, edema y engrosamiento en la MCA.

La identificación viral fue positiva para avipoxvirus de paloma, al considerar los resultados de: la histopatología, en la que los cortes histológicos de las lesiones de las MCA mostraron cuerpos de inclusión intracitoplasmáticos, característicos de la infección viral por avipoxvirus; de la PCR, que amplificó un fragmento de $578 \mathrm{pb}$, correspondiente a una región del gen de la proteína $4 \mathrm{~b}$ del virus de viruela aviar (figura 1). Así como del REA, cuya digestión con la

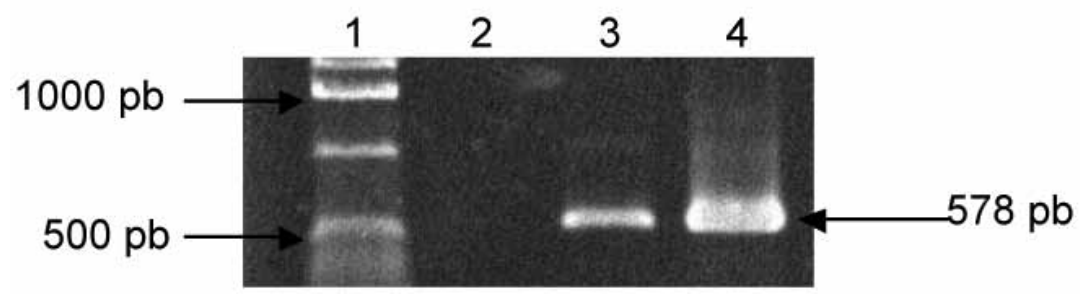

Figura 1. Electroforesis en gel de agarosa al $1 \%$ de los productos de amplificación de PCR. 1) Marcador de pares de bases. 2) Control negativo. 3) Fragmento de amplificación del ADN obtenido de MCA infectada con avipoxvirus de paloma. 4) Fragmento de amplificación del ADN obtenido de avipoxvirus de pollo.

Electrophoresis at $1 \%$ agarose gel of the products of PCR amplification. 1) Molecular marker. 2) Negative control. 3) Fragment amplification of DNA from pigeon avipoxvirus infected CAM. 4) Fragment amplification of DNA from chicken avipoxvirus. 
enzima MseI generó los tres fragmentos esperados (250, 118 y $95 \mathrm{pb}$ ) para el avipoxvirus de paloma (figura 2), según lo descrito por Lüschow y col (2004). El avipoxvirus de pollo, empleado como control, también amplificó un fragmento de 578 pb (figura 1), cuya digestión enzimática produjo tres fragmentos de 252, 177 y 149 pb (figura 2), característicos de este avipoxvirus.

Para la elaboración de la vacuna homóloga se realizaron seis pases en MCA de EP y se obtuvo un título del virus de $10^{4,37} \mathrm{DIEP}_{50 \%} / \mathrm{mL}$, valor que concuerda con lo recomendado por Winterfield y Hitchner (1964), quienes sugieren un título no menor de $10^{4} \mathrm{DIEP}_{50 \%} / \mathrm{mL}$ para lograr una inmunidad óptima. De forma similar, el número de pases efectuados en EP se encuentra dentro del rango de 5 a 30 propuesto por Tudor (1991).

Después de haber realizado la vacunación con ambos poxvirus (homólogo y heterólogo), se observó diariamente la respuesta local durante tres semanas. La vacuna contra poxvirus de paloma causó la formación de pústulas y costras en el $100 \%$ de los animales tratados, lesiones que coinciden con las descritas por Tudor (1991). En contraste, la vacuna comercial, elaborada con virus de pollo, solo provocó pápulas en el $55 \%$ de las palomas. Adicionalmente, el tiempo de aparición, la permanencia y el grado de las lesiones posvacunales difirió entre grupos. En el grupo vacunado contra avipoxvirus de paloma las lesiones se presentaron en promedio a partir del día 9 y permanecieron por 10 días, formando costras en su mayoría. Mientras que en el grupo vacunado contra avipoxvirus de pollo las lesiones aparecieron a partir del día 5 , duraron en promedio 6 días y fueron de menor tamaño. Ambas respuestas coinciden con las de trabajos previos, que describen una respuesta a partir del día 5 en palomas vacunadas con un poxvirus homólogo (Tudor 1991), del día 7 en pavos con poxvirus de paloma, codorniz o pollo, y del día 10 al 13 para la vacunación homóloga en pavos (Winterfield y col 1984). Por otro lado, Weli y col (2004)

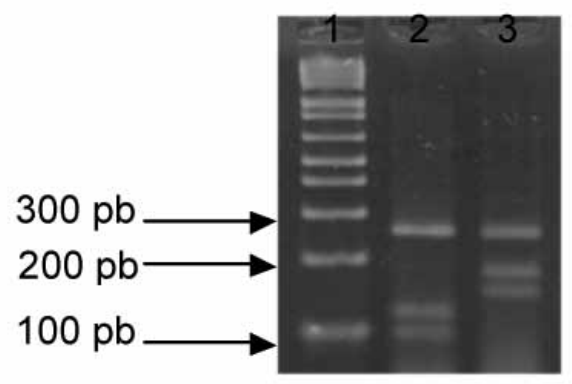

Figura 2. Electroforesis en un gel de agarosa al 3\% de los productos obtenidos después de la digestión enzimática con MseI. 1) Marcador de pares de bases. 2) Avipoxvirus de paloma. 3) Avipoxvirus de pollo.

Electrophoresis at $3 \%$ agarose gel of the products obtained after enzymatic digestion with MseI. 1) Molecular marker. 2) Pigeon avipoxvirus. 3) Chicken avipoxvirus. demostraron que las lesiones causadas por la infección con poxvirus de paloma en pollos fueron más graves y de mayor duración, al compararlas con las del poxvirus de pollo. Esto podría sugerir que el avipoxvirus de paloma es más virulento que el de pollo, lo cual concuerda con nuestros resultados.

Al realizar la seroneutralización viral con los sueros de las palomas que recibieron la vacuna elaborada con poxvirus de pollo, así como con los del grupo control, no se encontró la presencia de anticuerpos neutralizantes, ya que todas las MCA de los EP desarrollaron las lesiones correspondientes a viruela. En el caso de los sueros obtenidos de los animales que recibieron la vacuna elaborada con poxvirus de paloma, no hubo lesiones en la MCA en las primeras diluciones, y éstas se observaron a partir de la dilución del suero de 1/40. Utilizando el método de Reed y Muench (1938), se obtuvo un título neutralizante del suero $1 / 61,5\left(10^{1,79}\right) \mathrm{DN}_{50 \%}$ para los sueros del grupo vacunado con avipoxvirus de paloma. Paralelamente, la respuesta al desafío con avipoxvirus de paloma, tanto en el grupo control como en el vacunado con poxvirus de pollo, mostró que el $100 \%$ de los animales presentaron lesiones locales, mientras que en el grupo vacunado con poxvirus de paloma ningún animal presentó lesiones posdesafío. Estos hallazgos son muy importantes, ya que muestran que, al igual que en otras enfermedades virales, tanto en aves (Fynan y col 1993, Van Der Goot y col 2005) como en mamíferos (Baldridge y Buchmeier 1992, Ciurea y col 2000), los anticuerpos neutralizantes son indispensables para generar protección mediante la neutralización viral. El hecho de que la vacuna elaborada con avipoxvirus de pollo no genere anticuerpos neutralizantes contra poxvirus de paloma, puede deberse a que los anticuerpos generados por la vacuna heteróloga no alcanzan un nivel protectivo en los animales, o a que entre los diferentes avipoxvirus existe una baja antigenicidad cruzada. Esto último podría asociarse a la heterogeneidad genética que recientemente ha sido reportada entre aislamientos de poxvirus de pollo y de pichón en Noruega (Weli y col 2004).

La información en la literatura sobre la protección que generan las vacunas heterólogas es variada. Por un lado, autores como Winterfield y Hitchner (1964) mostraron hasta $100 \%$ de protección en pollos, al emplear una vacuna heteróloga de poxvirus de paloma y desafiar con poxvirus de pollo dos semanas posvacunación. Por su parte, Geleneczei y Lasher (1968) demostraron que en pavos vacunados con poxvirus de pollo cultivado en EP se generó un $100 \%$ de protección durante un mes, misma que se redujo al $40 \%$ a los tres meses; mientras que en pollos vacunados con virus homólogo dicha protección se mantuvo en un 100\% hasta por tres meses. Con los resultados anteriores se podría sugerir que al utilizar vacunas heterólogas la protección tiene un menor tiempo de duración.

Por otro lado, los estudios de Tudor (1991) indican que la única vacuna efectiva contra la viruela de paloma es una elaborada a partir del virus aislado de la misma 
especie. Además, Winterfield y Reed (1985) encontraron que la vacunación heteróloga contra viruela en codornices y pollos (empleando virus aislados de palomas, codornices, pollos y pericos) no confirió protección cuando se desafió con un avipoxvirus distinto al utilizado en la vacunación; mientras que si el desafío se realizaba con un virus homólogo a la vacuna, la protección obtenida era superior al 90\%. Igualmente, Winterfield y col (1984) al vacunar pavos contra avipoxvirus aislados de pollos, palomas o codornices, obtuvieron una protección máxima del 10\%. Por su parte, Reed y Fatunmbi (1993) informan que únicamente las vacunas homólogas protegen contra la infección causada por poxvirus de codorniz. Estos datos concuerdan con los resultados obtenidos en este estudio, en el que la vacunación homóloga (palomas inoculadas con poxvirus de paloma) mostró un 100\% de protección, mientras que la vacunación heteróloga (palomas inoculadas con poxvirus de pollo) no protegió a ningún animal del desafío con poxvirus de paloma, lo que indica que la utilización de vacunas homólogas produce una mejor respuesta inmune. Lo anterior se confirma porque aun cuando el $55 \%$ de los animales vacunados con poxvirus de pollo presentó una reacción cutánea posvacunal, ninguno de éstos quedó protegido ante el desafío con el virus de paloma. Es probable que estas palomas hayan quedado protegidas contra poxvirus de pollo, aunque esto no fue objeto de la investigación del presente estudio. Los datos anteriores permiten sugerir que la respuesta inmune humoral específica para el virus usado en la vacuna es necesaria para evitar una infección con la especie de avipoxvirus homólogo.

En el presente estudio se puede concluir que en palomas, la vacuna de poxvirus de pollo no generó respuesta de anticuerpos neutralizantes, ni protegió contra un desafío con poxvirus de paloma, aun cuando el 55\% de los animales tuvieron una reacción posvacunal. Mientras que la vacuna elaborada a partir de MCA de EP inoculadas con poxvirus de paloma protegió al 100\% de los animales contra un poxvirus homólogo. Por esto último, se sugiere emplear vacunas homólogas para proteger contra la enfermedad de viruela en palomas.

\section{RESUMEN}

En el presente estudio se comparó la protección conferida entre una vacuna homóloga, elaborada con avipoxvirus de paloma, y una vacuna comercial heteróloga de avipoxvirus de pollo, al desafiar palomas con un avipoxvirus de paloma. El avipoxvirus de paloma se aisló a partir de costras de palomas enfermas de viruela y se inoculó en membranas corioalantoideas (MCA) de embrión de pollo (EP). La identificación viral se hizo por histopatología, reacción en cadena de la polimerasa y análisis de restricción enzimática. Dicho virus fue adaptado al EP mediante pases en MCA y se utilizó como vacuna homóloga cuando alcanzó un título de $10^{4,37} \mathrm{DIEP}_{50 \%} / \mathrm{mL}$. Se vacunaron palomas mensajeras con la vacuna homóloga $(\mathrm{n}=20)$ y con una vacuna heteróloga $(\mathrm{n}=20)$, alcanzando un título neutralizante del suero de 1/61,5 para el grupo de la vacuna homóloga, mismo que fue nulo para el grupo de vacuna heteróloga. Por último, los animales se desafiaron con una suspensión de avipoxvirus de paloma con la que se obtuvo una protección del 100\% en el grupo de la vacuna homóloga, mientras que en los grupos de vacuna heteróloga y en el grupo control $(n=20)$ no hubo protección. Se concluye que una vacuna homóloga contra avipoxvirus de paloma, adaptada a EP, es capaz de generar anticuerpos neutralizantes y su protección es significativamente mayor a la conferida por la vacuna heteróloga comercial.

\section{AGRADECIMIENTOS}

Las autoras agradecen al MVZ Ángel Retana Reyes y al M. en C. José Ramírez Lezama por la ayuda brindada en este trabajo.

\section{REFERENCIAS}

AAAP, American Association of Avian Pathologist. 1989. Laboratory Manual for the Isolation and identification of avian pathogens. $3^{\text {rd }}$ ed. Kendall/Hunt Publishing Company, Pennsylvania, USA, Pp 195-198.

Baldridge JR, M Buchmeier. 1992. Mechanism of antibody-mediated protection against lymphocytic choriomeningitis virus infection: Mother to baby transfer of humoral protection. J Virol 66, 4252-4257.

Ciurea A, P Klenerman, L Hunziker, E Horvath, B Senn, A Ochsenbein. 2000. Viral persistence in vivo through selection of neutralizing antibody-escape variants. PNAS 97, 2749-2754.

Cunningham CH. 1971. Cultivo de Virus. Métodos cuantitativos. In: Burguess Publishing Co (ed). Virología práctica. $6^{\mathrm{a}}$ ed. Editorial Acribia, España, Pp 67-68, 221-229.

Das SK, S Baksi, K Biswas, R Das. 2005. Epidemiological studies on pigeon pox. Indian Vet $J$ 82, 689-690.

De Heart P, L Devriese. 2000. Pigeons. In: Tully TN, Lawton CP, Dorrestein MG (ed). Avian medicine. $1^{\text {st }}$ ed. Butterworth Heinemann, Oxford, UK, Pp 318-320.

Fynan E, R Webster, D Fuller, J Haynes, J Santoro, H Robinson. 1993. DNA vaccines: Protective immunizations by parenteral, mucosal and gene-gun inoculations. PNAS 90, 11478-11482.

Galenczei EF, Lasher HN. 1968. Comparative studies of cell-culturepropagated avian pox viruses in chickens and turkeys. Avian Dis $12,142-150$

Gerlach H. 1994. Viruses. In: Ritchie BW (ed). Avian medicine principles and application. $1^{\text {st }}$ ed. Wingers Publishing, Florida, USA, Pp 865-874.

Krautwald MJ. 2007. Aids to diagnosis. In: Coles BH (ed). Avian medicine and surgery. $3^{\text {rd }}$ ed. Blackwell Publishing, Oxford, UK, Pp 56-59.

Lee LH, H Lee. 1997. Application of the polymerase chain reaction for the diagnosis of fowl poxvirus infection. J Virol Methods 63, 113-119.

Lüschow D, T Hoffmann, M Hafez. 2004. Differentiation of avian poxvirus strains on the basis of nucleotide sequences of $4 \mathrm{~b}$ gene fragment. Avian Dis 48, 453-462.

Marlier D, H Vindevogel. 2006. Viral infections in pigeons. Vet J 172, 40-51.

Murphy FA, J Gibbs, C Horzinek, J Studdert. 1999. Laboratory diagnosis of viral diseases. In: Murphy FA (ed).Veterinary virology. $3^{\text {th }}$ ed. Academic Press, California, USA, Pp 216-218.

Reed JL, H Muench. 1938. A simple method of estimating fifty percent end points. Am J Hyg 27, 493-497.

Reed WM, OO Fatunmbi. 1993. Pathogenicity and immunological relationship of quail and mynah poxviruses to fowl and pigeon poxviruses. Avian Pathol 22, 395-400.

Tripathy DN, WM Reed. 2003. Pox. In: Saif Y (ed). Diseases of poultry. $11^{\text {th }}$ ed. Iowa State Press, Iowa, USA, Pp 253-269.

Tripathy ND. 1993. Avipoxviruses. In: McFerran JB (ed). Virus infection of birds. $1^{\text {st }}$ ed. Elsevier Science Publishers BV, Amsterdam, The Netherlands, Pp 1-13.

Tudor DC. 1991. Viral diseases. In: Tudor DC (ed). Pigeon health and disease. $1^{\text {st }}$ ed. Iowa State University Press, Iowa, USA, Pp 19-25.

Van Der Goot JA, GC Koch, M de Jong, M Van Boven. 2005. Quantification of the effect of vaccination on transmission of avian influenza (H7N7) in chickens. PNAS 50, 18141-18146. 
Weli SC, I Okeke, M Tryland, C Nilssen, T Traavik. 2004. Characterization of avipoxviruses from wild birds in Norway. Can J Vet Res 68, 140-145.

Wernery U. 2000. Viral diseases. In: Samour J (ed). Avian medicine. $1^{\text {st }}$ ed. Mosby, London, UK, Pp 266-269.

Winterfield RW, B Hitchner. 1964. The response of chickens to vaccination with different concentrations of pigeon pox and fowl pox viruses. Avian Dis 9, 237-241.
Winterfield RW, M Reed, L Thacker. 1984. Infection and immunity with a virus isolate from turkey. Poult Sci 64, 2076-2080.

Winterfield RW, W Reed. 1985. Avian pox: Infection and immunity with quail, psittacine, fowl and pigeon pox viruses. Poult Sci 64, 65-70. 